\title{
Discurso de saudação pela outorga do título de Professora Emérita a Dilza Atta
}

\section{Edivaldo Boaventura}

No momento em que a professora Dilza Maria Andrade Atta recebe o reconhecimento formal pelo seu trabalho docente, podemos melhor seguir a sua trajetória, pois o desenho do caminho só pode ser percebido depois de percorridas as etapas. Acrescenta Isaías: "é nos caminhos de outrora que seremos salvos".

Nessa caminhada, há momentos, instantes decisivos como os concursos, participações em conselhos e comissões, disciplinas ministradas, pesquisas realizadas, sequências de colégios e escolas, de professores e mestres, alunos e colaboradores, verdadeiras balizas fincadas ao longo da estrada percorrida. Assim, na vida docente da colega, acredito que existam dois períodos distintos, contíguos e cumulativos. O primeiro da formatura em Línguas Neo-Latinas, em 1952, seguido do ensino no secundário até 1969; e o segundo, de 1970 a 1990, na Faculdade de Educação da UFBA, onde Dilza contribuiu com duas décadas de magistério.

\section{Formação em Língua Vernácula e magistério secundário}

Nascida em Itaquara, com quatro anos veio para Salvador, mais precisamente para Itapagipe. A Ribeira foi o seu espaço urbano por excelência. Estudou em escola multisseriada, concluiu o normal no Colégio Santa Bernadete e ensinou um ano como professora primária. Nesse estabelecimento de ensino, onde hoje funciona o Colégio Costa e Silva, fator decisivo na sua formação foi o contato com o médico, professor e líder comunitário, Luiz Rogério de Souza. Por mais de; cinco anos sucessivamente com ele estudou Língua Portuguesa e Literatura Brasileira, Ciências, Puericultura. Luiz Rogério foi o seu mestre e a ele continuará ligada do Colégio Santa Bernadete ao Departamento da Faculdade de Educação e Conselho Estadual de Educação, de aluna a colega de magistério.

Formada no antigo esquema $3+1$, três anos de disciplinas de conteúdo linguístico e um de formação pedagógica, de 1949 a 1952, logo passou a ensinar Português. A descoberta mais significativa, na Faculdade de Filosofia, Ciências e Letras da Bahia, foi a biblioteca.

Desde muito cedo, o presente predileto dos seus pais foram iivros. O pai árabe, falando mais a sua língua materna do que o vernáculo, abriu a cabeça da filha para o mundo dos livros. É surpreendente como um imigrante que chega ao país precisando lutar pela sobrevivência e uma nascida na roça tenham tal atitude para com os livros! Por seu turno, a antiga Faculdade de Filosofia, na diversidade dos seus cursos e matérias, possibilitou o contato com outras áreas do conhecimento peia convivência com colegas de História, Geografia, Ciências Naturais e Jornalismo, curso novo que se iniciava.

Marcou definitivamente a vida da adolescente a Ação Católica, primeiramente, na Juventude Estudantil Católica e depois na Juventude Universitária Católica, a Juc. A formação na ação, segundo os pressupostos do método de ver, julgar e agir, criou sempre uma atitude realista ao abordar o conjunto das circunstâncias. Assinale-se a contribuição de um Gabriel Mareei, de um Emmanuel Mouniere outros auto- 
res franceses.O padre Lebret com os seus Princípios para a ação, afirmava:

É preciso abordar um problema pelo seu objeto, no sentido mais amplo da palavra:

'De que se trata?'

Nada, a não ser a submissão ao objeto. Nada, a não ser a ambição do bem.

É fácil identificar na convivência com Dilza, principalmente no departamento, o proceder paulino de se apagar diante da obra que vai ser empreendida e que tem o bem como objetivo. O espírito de equipe e a inclinação para ouvir o grupo e com ele trabalhar, como no Núcleo de Supervisão, é bem característico do pessoal formado pela Ação Católica.

O trabalho docente mais importante da diplomada em línguas neo-latinas aconteceu no Instituto Normal da Bahia (Instituto Central de Educação Isaías Alves, ICEIA), no curso pedagógico noturno, ensinando a pessoas adultas que voltavam a estudar quase sempre mais velhas do que a jovem licenciada. Em 1955, realiza o concurso para o magistério secundário, permanecendo até 1968 quando é chamada para trabalhar na assessoria da Secretaria de Educação e Cultura. Alem do Instituto Normal, a antiga aluna fez do Colégio Santa Bernadete a sua tenda de inovaçõe e experimentos. Ensinando e coordenando, é eleita supervisora pelos seus colegas. Eis o início da atividade de supervisão educacional. Confirmando Anísio Teixeira, quanto à natureza e função da administração escolar, "somente o educador ou o professor pode fazer administração escolar"; primeiramente, é preciso a experiência do professor na sala de aula. É oportuno ouvir o grande Anísio:

Há no ensino, na função de ensinar, em gérmen, sempre ação administrativa. Seja a lição, seja a classe envolve administração, ou seja plano, organização, execução, obediente a meios e técnicas(...)

Deste modo, a carreira de educador compreenderá na base $o$ professor, que ao longo do seu ministério, poderá especializar-se em supervisor, ou professor de professores, em conselheiro ou orientador, ou guia dos alunos, ou em administrador escolar. O professor continua toda a vida professor, ou opta por uma das três especializações, em que se divide seu mister de educar.

No caso de Dilza, do ato de ensinar continuamente refletido, surgiu a supervisora. A Faculdade de Educação, ao ser instituída, irá colher e desenvolver esta experiência docente como veremos adiante.

Como sucede com os bons e experimentados professores da Secretaria Estadual de Educação - a maior e a melhor constelação de recursos humanos que possuímos, com a qual sou sentimentalmente comprometido - Dilza, com mais de década e meia de trabalho na sala de aula fazendo, democraticamente, coordenação pedagógica, vai servir na Secretaria por volta de 1968, alargando sistemicamente a sua experiência vivida até então no Colégio Santa Bernadete e no ICEI A. Dentre muitas outras atribuições, representa a Secretaria em sucessivas reuniões com o pessoal da Universidade Federal da Bahia, pois, tanto o reitor Roberto Santos como os secretários de Educação da época, Luiz Navarro de Brítto e nós estávamos interessados no entrosamento entre ensino médio e superior, revisão do vestibular seletivo pelo classificatório, unificado ou único.

A professora Leda Jesuino dos Santos, coordenadora da implantação da Faculdade de Educação, a nossa Faced, convida Dilza para integrar o quadro de professores. Em 1970, começa a participar 
do grupo constituinte, conforme ofício de 15 de janeiro do reitor. Lembremo-nos, perfeitamente, de uma reunião onde discutíamos a terminologia coordenação ou supervisão? Assim, quando vem para a nova unidade académica, Dilza traz uma prática docente altamente refletida sobre a sua experiência pessoal e docente tanto em estabelecimentos de ensino secundário como no órgão cabeça do sistema estadual de educação. Destaque especial merece ser dado à sua atividade de coordenadora pedagógica, o outro nome da supervisão, que nascia juntamente com os estudos de currículo na Secretaria de Educação.

\section{Na Faculdade de Educação da UFBA}

Acredito que é chegado o momento de começar a falar no segundo período do singular desempenho académico da colega homenageada, que terá lugar na nossa Faced, espaço privilegiado para se de senvolver plenamente não somente na Supervisão, mas sobretudo como educadora.

O final da década de sessenta, especialmente 1968, é o ano da grande revolta dos jovens. A reforma desestrutura a Universidade for mada por ordem de faculdades e organiza uma corporação mais integrada. Fomos alunos de uma universidade fechada em faculdades e fomos ser professores em uma universidade mais sistemicamente coordenada com conselhos, departamentos, núcleos de ensino e pesquisa e novos serviços. É nesse contexto de mudança que se implanta a Faculdade de Educação, unidade académica nova, tentada na Universidade do Distrito Federal e retomada na Universidade de Brasília por Darcy Ribeiro e Anísio Teixeira.

$\mathrm{Na}$ Universidade Federal da Bahia, a Faculdade de Educação nascia de várias segmentos: primeiramente, do Departamento de $\mathrm{Pe}$ dagogia, trazendo dentre outros os professores António Pithon Pinto e Haidé Correia da Silva, Jandira Simões, Alice Costa, Raimundo Matta; segundo, do Centro de Ensino de Ciências da Bahia, o Ceciba, com Luiz Felippe Perret Serpa, Hermes Teixeira de Melo; terceiro, do grupo de Linguística Aplicada ao Ensino de Português, tendo à frente Joseiice Macedo de Barreiro; quarto, o Colégio de Aplicação com Zilma Parente de Barros; quinto, destaquem-se os professores das licenciaturas, como Mariaugusta Rosa Rocha, Juscelino Barreto Santos, Maria Angélica Mattos e Silvestre Ramos Teixeira, que realizou também o seu concurso para a nova Faculdade; sexto, professores de outras unidades, como Luiz Rogério de Souza, Tobias Neto e nós, viemos integrar o corpo docente. A nova unidade académica exige outras habilitações. Dessa maneira, o trabalho de Dilza já conhecido pelo que realizara no Colégio Santa Bernadete e na própria Secretaria chamava a atenção de todos.

O currículo de Pedagogia, estabelecido pelo Conselho Federal de Educação em 1969, institui as habilitações de Supervisão, Orientação, Administração, Ensino Normal, Inspeção e outras. Como primeiro coordenador do Curso de Pedagogia, trabalhei com o grupo inicial. A liderança de Dilza achará amplo campo de atuação e reflexão na montagem da matéria Supervisão. Era, então, o nosso pequeno e íntimo Departamento II - Planejamento e Administração Educacional com os companheiros José Tobias Neto, Luiz Rogério, Maria Anália Costa Moura, Mary Woortmann, Ziima Parente de Barros, António Pithon Pinto, Haiclé Correia da Silva, Nilza Maria Souza Santos. Logo depois se fundiria como Departamento I, istoé, dos professores de Psicologia, Alice Costa, Raimundo Matta, Jandira Ribeiro, de Filosofia da Educação, Romélio Aquino, de História da Educação, Jandira Simões.

\section{Supervisão Educacional em um contexto de mudança}


Em 1972, realiza o concurso inicial para a carreira docente com a tese $A$ Supervisão Educacional em um contexto de mudança. Uma dissertação que resultava de anos e anos de experiência e conhecimento em educação. Senti de perto porque fui um dos examinadores. De auxiliar de ensino contratada passa a assistente e adjunto. Em 1975, Jandira Simões e Dilza reuniram as suas duas teses de concurso e publicaram o tão consultado e útil volume Supervisão Educaciona/^Salvador: Gráfica Editora Arco íris), ambas integravam o Núcleo de Supervisão da Faced. A sinopse descreve:

A educação em um contexto de mudança, dentre cujas variáveis a explosão demográfica é especialmente analisada. Reflexão sobre o papel do supervisor no sistema de educação como facilitador do aperfeiçoamento de pessaol e, por isso, agente multiplicador de recursos humanos na área docente (...)

Antes do Núcleo, começou o trabalho de supervisão com os alunos no Centro Pedagógico da Faculdade, que era muito atuante em vista do fechamento dos diretórios. Recorda que recebeu quatro monitores: Magali Figueiredo, Adélia Portela, Sônia Bamberg e Raimundo Luís Lopes de Oliveira

Com a instalação da Faced, no Canela, expandem-se os Núcleos de Supervisão e Orientação. Entende que a supervisão é, em síntese, uma expressão da qualidade do ensino, qualidade que se define pela necessidade de quem está recebendo educação. Quanto mais próximo do aluno o professor poderá mediar a sua aprendizagem. A sustentação teórica do seu trabalho encontra-se nos filósofos cristãos como Gabriel Mareei. Estuda Piaget ainda no Santa Bernadete, contudo estuda depois autores que explanam o pensamento piageteano. Quando fazia o concurso, descobre Karl Rogers e a não diretividade que exige, muitas vezes, que alguma coisa seja realizada. A presença de Dilza está intimamente ligada ao Núcleo de Supervisão. Com efetiva liderança monta-o e o expande, inicialmente com Jandira Simões, depois agrega Nilza Maria Souza Santos, Marilene Santil, Iracy Alves, Maria das Graças, Regina Antoniazzí. Colegas como Odile Angelim Lima, Haidé Correia da Silva, Coriolinda Carvalho (Babynha) sempre estiveram ligadas ao Núcleo. Dilza manifesta sempre um comportamento que prefere agir em comum com colegas. O Núcleo estabeleceu uma relação com a comunidade e a Secretaria Estadual de Educação. Identifico no seu trabalho de grupo uma mentalidade formada na Ação Católica. Liderança forte, que sabe ouvir, induzir, sugerir, mas não gosta dos cargos gerenciais. Diria que o palco não conta para ela, prefere os bastidores, o interior oculto e construtivo das tendas de trabalho. Confessa que o cargo administrativo é uma violência ao seu modo de agir.

Durante todo o tempo na Faced exerceu tão somente a vicediretoria da Faculdade na gestão de Jandira Simões. Gestão fecunda pelos encontros apoiados pela Organização dos Estados Americanos (OEA). CREFAL e Faculdade realizaram um seminário sobre educação de adultos, durante 15 dias com a participação de especialistas da Nicarágua, México, Chile, Colômbia. E com os recursos da OEA foram publicados os livros da Coleção Cidadania, editados por José Arapiraca. Ao final da gestão, recordamos que escolhido para coordenar o projeío de Doutorado em Educação, consultei diretora e vice, tendo recebido todo o apoio e assim prosseguimos nos entendimentos.

Uma palavra sobre a sua produção académica que consta de trabalhos não somente sobre supervisão, como acerca de observações sobre os municípios de Jeremoabo, "A Roda de São Gonçalo na região do Médio São Francisco", estudos sobre o professor único na 
zona rural, classe multisseriada, órgão municipal de educação, diversos pareceres do Conselho Estadual de Educação e trabalhos com Adélia Portella sobre pesquisa (Publicações em anexo).

Uma vez jubilada não ficou nos aposentos. Preparada com experiência em educação e manejo da língua portuguesa, trabalhou nas cooperativas de educação, na FUNDESP, em habilitações de segundo grau específicas para o serviço público, na revisão de teses, dissertações e livros, realiza pesquisa sobre o trabalho desenvolvido em sala de aula, no Instituto Anísio Teixeira.

Senhor Reitor, meus caros colegas, alunos, amigos e servidores.

São três propostas de professores eméritos que se vão efetivando, coincidentemente: Dilza, pelo Departamento I e Leda Jesuino dos Santos pelo Departamento II, já receberam o título. Falta Alcyr Ferraro, criador dos cursos de Educação Física da UFBA e da Universidade Católica, expressão inquestionável da sua disciplina como demonstrou em suas memórias

Ao integrar estas palavras na festa do reconhecimento de um trabalho académico refletido, pensado e experimentado, como é o da nossa homenageada, gostaria de acrescentar que propus ao nosso Departamento o título de professor emérito para Dilza por ela representar o tipo de professor que constrói, eleva e revela a Faculdade à comunidade. E mais ainda pela efetiva liderança na implantação da Supervisão Educacional, na Faculdade de Educação da UFBA.

Minha cara Dilza, para você releio seus versos de "Descoberta":

O olho do visitante nem sempre está preparado

Para descobrir e ler a verdade:

O brinquedo na mão da criança pode ser ferramenta de vida

Seja feliz, minha colega, na etapa que reinicia na caminhada de docente com o reconhecimento do mérito pela nossa Universidade. 